\title{
The Inescapability of Theorizing Practices within Epistemology
}

Chris Calvert-Minor

\begin{abstract}
For many epistemologies, theory and practice remain bifurcated concepts that facilitate the application of theoretical, epistemic structures upon groups of people and their practices without consideration for the actuality of these people and practices. In contrast, an appropriate epistemology should recognize existing practices that produce what we take to be knowledge, and develop theories of knowledge and rationality based upon them, not in spite of them. In short, an appropriate epistemology should be a "practicist" epistemology. Endorsing an epistemology that gives fundamental attention to the structure and purpose of our actual practices is not new, but oftentimes, convincing arguments for a practicist epistemology are not forthright. In this paper, I argue that when we consider the nature of epistemological theorizing, and the nature of theories themselves, whether they are meant to organize or fit reality and our experiences, we are unable to separate out the role and importance of practices. Therefore, we should likewise give due respect to the primacy of epistemic practices which comprise the impetus for our epistemological theorizing.
\end{abstract}

Keywords: Epistemology, theory and practice, social practices, practicist epistemology

7 he rift between theory and practice persists in areas of epistemology where abstract preoccupations relegate concrete human practices and their consequences to the fringes of concern. It is commonplace to measure the fruitfulness of epistemologies based on how well they reconcile dilemmas such as global skepticism, the lottery paradox, and Gettier's instances of justified true belief that do not warrant the designation of 'knowledge'. Other means of evaluation include how well epistemologies sustain their theories of justification and avoid the regress problem, as is frequently done with foundationalist, coherentist, and contextualist programs. But while many of these theoretical concerns are appropriate at times - I do not discount them - they cannot be esteemed at the expense of not taking seriously our existing epistemic practices. It is not enough to 
tie knowledge and rationality to practices just because the actual process of justification is a kind of practice. Rather, an appropriate epistemology should recognize our existing practices that produce what we take to be knowledge and develop theories of knowledge and rationality based upon them, not in spite of them.

In this paper, I argue that when we consider the nature of epistemological theorizing, and the nature of theories themselves, whether they are meant to organize or fit reality and our experiences, we are unable to separate out the role and importance of practices. Therefore, we should likewise give due respect to the primacy of epistemic practices which comprise the impetus for our epistemological theorizing. I call this kind of epistemology, "practicist epistemology."

To distinguish practicist epistemology more carefully from other epistemologies, it is a departure from epistemological inquiry that traditionally centers on individuals and/or communities as the primary epistemic categories to analyze. Practicist epistemology shifts epistemology away from primarily focusing on epistemic agency to that of epistemic practices. Epistemic practices are contextually-bound, patterned procedures of activity constituted by epistemic agents, the material world, discursive rules, and society. In particular, they are normative, procedural areas of action involved in the gathering, constitution, and implementation of evidence and justification. These procedural actions are openended, sometimes roughly defined normative rules that signify what counts as evidence and the parameters of rational justification in the production of knowledge claims. The nature and character of epistemic agents and justification do not come prior to the analysis of epistemic practices, which would be a case of epistemic apriorism; rather they are themselves co-instantiated products within the epistemic practices. In other words, practicist epistemology is a bottom-up approach that generates who the relevant epistemic agents are and the nature of their knowledge production, rather than the top-down model indicative of many traditional epistemologies that already assume what counts as relevant, sanctioned epistemic agency and justification. There is an insistence against imputing into the field of epistemic practices preconceived notions of epistemic agency, criteria for good/bad norms of rationality, disembodied views of objectivity, and abstract conceptions of truth.

Thus, practicist epistemology entails the development of theories of knowledge and rationality based upon our existing epistemic practices without preconceiving the function and prescription of an individual's or community's epistemic agency within those practices. This does not mean that general conceptions of epistemic agency, norms of rationality, objectivity, and truth cannot be theorized. It only means that such conceptions must be developed within the confines of actual epistemic practices and that those conceptions must be subject 
to change as epistemic practices are susceptible to considerable change in their repeated implementations or "reenactments" as Joseph Rouse maintains. ${ }^{1}$

Endorsing an epistemology that gives fundamental attention to the structure and purpose of our actual practices is not new. The classic American pragmatists, Frederick Will, Richard Rorty, Theodore Schatzki, Andrew Pickering, Joseph Rouse, and many feminist epistemologists such as Sharyn Clough and Karen Barad all subscribe to this approach, motivated by the desire to transcend what they deem as intractable problems in traditional epistemology. ${ }^{2}$ Yet, in many of their writings convincing arguments for a practicist epistemology are not forthright; the claim for practicism is typically offered as an ameliorating or untroubled position that overcomes certain epistemic difficulties. But that approach is not convincing.

William James, for example, believes that while during his time a distinction can be made between the idealistic monism of the tender-minded rationalist and the pluralistic materialism of the tough-minded empiricist, many wish to hold to the good they find in both, though they find it hard to reconcile them. ${ }^{3}$ In response, James simply announces pragmatism, a version of practicist epistemology, as an alternative position that satisfies both the demands for a religious or romantic spirit of adaptation and accommodation and a loyalty to scientific facts. Clough finds many current feminist epistemologies hopelessly caught within a representationalist model of knowledge that produces an unbridgeable epistemic gap between the knower and the world, making it impossible to overcome global skepticism. ${ }^{4}$ Like James, she offers practicist empiricism as a viable alternative in light of failed representationalism. But without supporting reasons why one should endorse a particular version of practicist empiricism, the practicist alternative remains simply that, just an alternative. We want to be justified in the belief that practicist empiricism is better than other nonrepresentationalist competitors. Thus, I give an argument here.

To begin, practicist epistemology, again, is an epistemology that develops theories of knowledge and rationality based upon our existing epistemic practices, and what counts as "epistemic practice" broadly includes those practices that develop rules for justified beliefs, employ norms of rationality to produce justified beliefs, involve the gathering and constitution of evidence, and are open to critique and corroboration. Such practices are not discipline specific, but they must use reasons and evidence in the development of knowledge and rationality claims.

\footnotetext{
${ }^{1}$ Joseph Rouse, Engaging Science: How to Understand its Practices Philosophically (Ithaca: Cornell University Press, 1996), 26.

2 While I classify these theorists as "practicist epistemologists" according to the methodology and content of their work, I do not presume that they themselves would use the term.

${ }^{3}$ William, James, "Lecture One: The Present Dilemma in Philosophy," in Pragmatism, ed. by R. Baird and S. Rosenbaum (Amherst, MA: Prometheus Books, 1991).

${ }^{4}$ Sharyn Clough, Beyond Epistemology: A Pragmatist Approach to Feminist Science Studies (New York: Rowman \& Littlefield Publishers Inc., 2003).
} 
However, C. S. Peirce criticizes the term 'practicism' because he believes it ignores the cognitive intentionality of practices. ${ }^{5}$ This need not be the case, but the point is worth emphasizing. Every practice involves some doing for the sake of some end. Thus, there is always an intentional dimension to practice and this dimension is ineliminable. If I am figuring out what I owe in income taxes to my government so that I can pay them at the designated time, I do that practice to fulfill my civic duty or maybe to avoid interference from civic authorities that would surely happen if I failed to pay the taxes on time. But I do not engage in that practice without reason. I do that practice, and all others, with a purpose, without which our actions would be arbitrary or accidental, not suitable to be called 'practice'. Hence, this is the oft-cited understanding of pragmatism that privileges an attention to actual practices with an eye on their futurity, an eye on how and where practices lead. This pragmatist understanding equally applies to the notion of practicist epistemology I defend here. ${ }^{6}$

Building on this intentional dimension to practice, my argument for a practicist epistemology is that one cannot theorize or think of epistemological theories without already referencing practices that constitute such activities and, thus, one should recognize and respect the existing epistemic practices already in action by which one creates an epistemology. One should construct one's epistemology in light of those practices, not in spite of them. I now develop this argument.

In epistemological theorizing, it would be remiss to ignore that it itself is a kind of practice and that the way it is enacted contributes to the overall outcome. A failure to recognize this truth would result in undue abstraction. If all procedural modes of thought and action are themselves forms of practice, one cannot help but engage in forms of practice, and theorizing about knowledge and rationality is no exception. When someone analyzes or defines what knowledge or rationality is, whether one merely believes she is trying to get her epistemology right merely for the sake of getting it right or explicitly trying to construct a useful epistemology, they amount to the same thing - an intentional practice. In fact, Rorty proposes through Dewey that perhaps the natural way of understanding theoretical claims is not to get theories right, but instead ask, "What it would be like to believe that? What would happen if I did? What would I be committing myself to?" and from

${ }_{5}^{5}$ Peirce renamed his position to "pragmaticism," to distinguish his philosophy from other philosophies that became branded under the name of "pragmatism." C. S. Peirce, "What Pragmatism is," in The Monist, 15 (1905), 161-181.

${ }^{6}$ While the notion of practicist epistemology I defend here bears some relation to classical pragmatism, it does not entail the classical pragmatist conception of truth. Elsewhere, using the work of Donald Davidson, I argue for a primitive, fixed notion of truth. See Chris Calvert-Minor, "Commonsense Realism and Triangulation," Philosophia, 37:1 (2009), 67-86. 
these questions one cannot help but use the language of practice. ${ }^{7}$ Rorty recognizes that asking for an epistemology relies on wanting to use it to answer questions about knowledge, truth, and rationality, so the question of getting a theory right is always a surrogate for wondering what the consequences of believing that theory will be. This point does not mean that correctness is necessarily reducible to consequence, though Rorty would want it that way. It just means that correctness and consequence are not absolutely separable. Frederick Will echoes this point,

Philosophical theories, like theories generally, are developed for various purposes and cannot be judged as adequate or inadequate without some reference to the kinds of questions they were devised to answer, what their objects are, and what features of these objects they were meant to illuminate. ${ }^{8}$

This is just another way of looking at the intentional activity of practice. Thus, a purposeful act always lies in theorizing, even within the scope of epistemological theorizing.

But this point by itself is not convincing to carry the argument. One could fully concede that theorizing is a form of practice undertaken with intent, but contest that there is a difference between how and why one comes to hold a theory and the conceptual content of that theory, that practices might constitute the former and yet the latter is separable from purposeful activity. The charge is for a continued separation between theory and practice in terms of theoretical content. The act of theorizing is split from the actual content of the theory. For example, one could accept that one's endorsement of contextualism is a practical concern an intentional activity to better understand the semantic properties of "know" and study its indexical mutations in different contexts - but the theoretical claims about epistemic and semantic properties are themselves not functions of intentionality and, thus, not functions of practice. We could come to a contextualist position through practice, but the meaning of contextualism is not captured within practice.

Here are two brief rejoinders. Frederick Will notes that terms such as "concepts," “ideas," and "conceptual schemes," (we can add, "theories," for theories are systems of concepts) connote, almost irresistibly to many, features or functions of private minds and that the individualistic philosophies of Descartes and the modern empiricists continue to prevail. ${ }^{9}$ He challenges this assumption by arguing

\footnotetext{
${ }^{7}$ Richard Rorty, "Pragmatism, Relativism, Irrationalism," in Consequences of Pragmatism, ed. by R. Rorty (Minneapolis: University of Minnesota Press, 1982), 162-163.

${ }^{8}$ Frederick Will, Beyond Deduction: Ampliative Aspects of Philosophical Reflection (New York: Routledge, 1988), 31.

${ }^{9}$ Frederick Will, “The Rational Governance of Practice," in Pragmatism and Realism, ed. by K. Westphal (New York: Rowman \& Littlefield Publishers Inc., 1997), 65; Frederick Will, "Reason
} 
that we need the necessary arbiter of our traditions to determine which reasons are publicly acceptable in instances of supposed individual parity. ${ }^{10}$ Traditions, for Will, are customary, approved ways of thinking that have been passed from generation to generation in more or less the same form with great success. These ways of thinking become ingrained in our practices and operate as commonly accepted norms and standards. Now, if according to these individualistic philosophies we all have the equal light of reason and, for example, two individuals each give reasoned arguments for opposite courses of action, how is it decided which argument is right? Will argues that those reasons and arguments that ultimately prevail within intersubjective disagreement must be functions of the tradition or else there is no way to explain what reasons are counted as good reasons. This is a predicament individualistic philosophies cannot handle. Will concludes that, "tradition, we now see, is not an influence on us separate from or opposed to reason. It is rather a necessary component of it." ${ }^{" 11}$ We can likewise apply these remarks to the rational acceptability of theories and, in instances of empirical parity, ask why one theory prevails over another. In accordance with Will's argument, the rational acceptance of one theory over another ceteris paribus must also be decided by tradition for there would be no way to break the stalemate. Tradition and rational acceptability become intertwined in theory choice. The corpus of tradition minimally entails certain established practices that are necessary components of the reasoning process that help create a link between what is rational and what is acceptable.

For the other rejoinder, Ludwig Wittgenstein argues that to understand rule following, or as we can say here, theory application, all we need is to describe the procedures of teaching and learning the rule or theory. ${ }^{12}$ These procedural descriptions demonstrate correct application. However, since these procedures are only able to offer a finite number of applications and our knowledge of the rule or theory only goes so far as the applications we are taught, we have no recourse as individuals to apply a rule or theory to future cases and know that we are doing it correctly. Past usage does not determine future usage. The content of concepts is then open-ended, a result against extensional semantics, or meaning determinism, which says in virtue of a concept's self-contained meaning its correct application

and Tradition," in Pragmatism and Realism, ed. by K. Westphal (New York: Rowman \& Littlefield Publishers Inc., 1997), 107-110.

${ }^{10}$ Frederick Will, "Reason and Tradition," in Pragmatism and Realism, ed. by K. Westphal (New York: Rowman \& Littlefield Publishers Inc., 1997), 112-113.

${ }^{11}$ Ibid., 113.

${ }^{12}$ Ludwig Wittgenstein, Remarks on the Foundations of Mathematics, trans. by G. E. M. Anscombe, ed. by G. H. von Wright, R. Rhees, and G. E. M. Anscombe (Oxford: Basil Blackwell, 1978), VII:26.

(C) 2012 Chris Calvert-Minor http://www.kritike.org/journal/issue 11/calvert-minor june2012.pdf ISSN 1908-7330 
can be deduced. ${ }^{13}$ Thus, for us to learn the accepted and acceptable practices of applying any particular rule or theory to subsequent cases, we need to be involved in the language games and community standards (e.g., consensus) that transcend the individual. Again, the correct content of the theory is linked to acceptable practices.

Yet, unfortunately, these rejoinders will not work as they stand. One can contest how closely linked theoretical content is to its rational acceptability and application. One would not have to hold that the applications of a rule, concept, or theory determines or produces the content therein, only that it may take actual practice, tradition, and a community to figure out what that content is and its subsequent application to new cases. The criticism is that this is an epistemic problem that has no necessary connection to the determination and status of content, staving off the link between theoretical content and practice needed for the argument; thus, one can still hold an extensional view. To reiterate, the extensional view of a concept is that before any use of a particular concept all those instances it truly applies to can be delineated, and it is that set of true instances that is the concept's 'extension'. It is just a matter of using our observation and reasoning skills to discover and map the extension. Applying this extensional notion to theories, a theory and the concepts therein determine in advance the theory's extensional application, such as what types of evidence and empirical patterns are relevant and the kinds of evidence that are confirming or disconfirming. It is then up to us to discover and map a theory's extension. Afterwards, we can determine if a theory is correct by comparing it with raw empirical data and seeing if there is enough evidential support for the theory as specified by what would count as acceptable evidence by the theory. This is a practice employed in light of fixed theoretical content, not the production of new content. New theoretical content would be produced if some of our acceptability standards helped develop or extend part of the theory apart from the theory's own extension (e.g., what counts as relevant types of evidence), yet this is what the extensional view disallows. Thus, practices have a place, even an indispensable place, but they do not affect the inherent content of the theory. Theoretical content and practice remain separate.

This claim of separability is plausible because it considers the relationship between theory and practice abstractly, meaning that it ignores how theories are used and the implications of those uses. However, this claim of separability is bankrupt if one cannot conceive of theory without already incorporating elements of practice since theory and practice are then "practically" inseparable. If this is the case, there is no reason to suppose that they are separable in the abstract. To show that this is the case, I consider Donald Davidson's two ways of conceiving conceptual schemes and relate them to the use of theories.

\footnotetext{
${ }^{13}$ For a more complete explanation of this view, see Barry Barnes, T. S. Kuhn and Social Science (New York: Columbia University Press, 1982).
} 
Davidson offers a few analyses on the nature and intelligibility of the idea of incommensurable or untranslatable conceptual schemes. ${ }^{14}$ For my purposes, the salient aspect of Davidson's analyses is his asking what it is that conceptual schemes relate to and are supposed to do, and not his larger worry of the conceivability of wholly different conceptual schemes. The point is to consider the two possible conceptions of theories and determine if practices remain integral. If they are, one cannot separate theory from practice.

If conceptual schemes are systems of categories used to structure our sense experience and help us interpret this experience, what is the relation between conceptual scheme and experience? Davidson provides two main groups of metaphors used to explain this relation: organizing and fitting. ${ }^{15}$ If conceptual schemes organize something, the metaphor is to "systematize" or "divide up" our "stream of experience," much like the Kantian faculties of "sensibility" and "understanding." According to Kant, our sensibilities organize all our sensory experiences under the pure forms of intuition, space and time, while the categories of the understanding have the fine-grained function of dividing up our experience so that they make experience intelligible. Michael Lynch writes of Kant, "These concepts organize raw preexperiential sensory intuition into experience of a world with sizes and shapes, befores and afters, causes and effects." ${ }^{16}$ This sounds straightforward, but Davidson is skeptical about how the organizing occurs.

For Davidson, there are two ways to understand the idea of organizing: either reality itself ("the universe, the world, nature") is being organized or our experience as "the passing show, surface irritations, sensory promptings, sense data, the given." ${ }^{.17}$ If "reality" is being organized, it is hard to understand what it means to organize it, to organize a single object such as "the world," unless the notion of plurality were already a part of one's conception of "the world." Without the prior assumption of a certain plural patterning to the world, there would be no sense given to organizing a single object. There can be sense given to the singularity of "reality" already being organized as something singular, but even this reveals a prior endorsement of plurality since to recognize something as singular requires the comparative conception of plurality and what counts as plural. Thus, we cannot speak of organizing reality without already knowing how to individuate objects according to patterns.

Davidson likewise finds talk of organizing experience (as sensory promptings and the like) troubling for much the same reason. "Whatever plurality we take experience to consist in - events like losing a button or stubbing a toe,

\footnotetext{
${ }^{14}$ Donald Davidson, "On the Very Idea of a Conceptual Scheme," in Inquires into Truth and Interpretation, ed. by D. Davidson (Oxford: Oxford University Press, 1984).

${ }^{15}$ Ibid., 191-195.

${ }^{16}$ Michael Lynch, Truth in Context (Cambridge, MA: The MIT Press, 1998), 32.

${ }^{17}$ Davidson, "On the Very Idea of a Conceptual Scheme," 192.
} 
having a sensation of warmth or hearing an oboe - we will have to individuate according to familiar principles." ${ }^{\prime 18}$

If we will already "have to individuate according to familiar principles" before we can make sense of "organizing," where do these principles and patterns come from and why are they used as opposed to alternatives? Wittgenstein's answer: like theory application and concept predication, they are a function of practice both in the process of learning and in the development of open-ended concepts. Thus, if conceptual schemes, and so theories, are conceived as organizing, one cannot separate them from practices.

As for conceptual schemes fitting or predicting the totality of our experience, focus shifts to whole sentences rather than predicates and quantifiers because the concern here is with evidential relations; sentences as well as the entire conceptual scheme are confirmed or disconfirmed by the evidence. Davidson writes, "A sentence or theory fits our sensory promptings, successfully faces the tribunal of experience, predicts future experience, or copes with the pattern of our surface irritations, provided it is borne out by the evidence." ${ }^{19}$ But Will already touches on this point about evidence. The relevance and rational acceptability of theories is determined, at least in part, by customary accepted ways of thinking; accepted, customary practices are a necessary part of what we take to be evidence. Thus, the conclusion is again that one cannot separate practices from the conception of conceptual schemes and theories.

Therefore, in both ways we can conceive of theories and conceptual schemes, as organizing and fitting, there are integral relations back to the types of practices already mentioned by Will and Wittgenstein. The claim is then that practices are always involved and that we do not know how to think of theories in the absence of actual practices (e.g., learning, training, tradition, rational acceptability, evidentiary procedures). The conclusion is that it does not make sense to bifurcate theory and practice according to the abstractions offered by potential critics. And if that is the case, if one needs to recognize the practices that go into the constitution of epistemological theories, one should also recognize and respect the existing epistemic practices already in action by which one creates an epistemology and is applied to those epistemic practices. To recognize the importance of practices in our own epistemological theorizing requires us to give due importance to actual epistemic practices and the people acting out those practices. An epistemology should minimally be a practicist epistemology, an epistemology based on practices, not developed or applied in spite of them.

With a dearth of arguments for epistemologies centered on existing epistemic practices, I argue here why epistemology should be, at least, a practicist epistemology. When we consider the nature of theorizing and constructing an

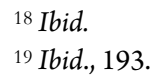

${ }^{19}$ Ibid., 193.

(c) 2012 Chris Calvert-Minor http://www.kritike.org/journal/issue_11/calvert-minor june2012.pdf ISSN 1908-7330 
epistemology and the nature of theories themselves, whether they are meant to organize or fit reality and our experiences, we are unable to separate out the role and importance of practices; one cannot escape theorizing practices within epistemology. This insight should transfer over into respect for the existing epistemic practices epistemologies attempt to explain. A responsible epistemology should minimally be a practicist epistemology.

Department of Philosophy \& Religious Studies, University of Wisconsin-Whitewater, United States

\section{References}

Barnes, Barry, T. S. Kuhn and Social Science (New York: Columbia University Press, 1982).

Calvert-Minor, Chris, "Commonsense Realism and Triangulation," Philosophia, 37:1 (2009), 67-86.

Clough, Sharyn, Beyond Epistemology: A Pragmatist Approach to Feminist Science Studies (New York: Rowman \& Littlefield Publishers Inc., 2003).

Davidson, Donald, "On the Very Idea of a Conceptual Scheme," in Inquires into Truth and Interpretation, ed. by D. Davidson (Oxford: Oxford University Press, 1984).

James, William, "Lecture One: The Present Dilemma in Philosophy," in Pragmatism, ed. by R. Baird and S. Rosenbaum (Amherst, MA: Prometheus Books, 1991).

Lynch, Michael, Truth in Context (Cambridge, MA: The MIT Press, 1998).

Peirce, C. S., "What Pragmatism is," The Monist, 15 (1905), 161-181.

Rorty, Richard, "Pragmatism, Relativism, Irrationalism," in Consequences of Pragmatism, ed. by R. Rorty (Minneapolis: University of Minnesota Press, 1982).

Rouse, Joseph, Engaging Science: How to Understand its Practices Philosophically (Ithaca: Cornell University Press, 1996).

Will, Frederick, Beyond Deduction: Ampliative Aspects of Philosophical Reflection (New York: Routledge, 1988).

, "The Rational Governance of Practice," in Pragmatism and Realism, ed. by K. Westphal (New York: Rowman \& Littlefield Publishers Inc., 1997).

, "Reason and Tradition," in Pragmatism and Realism, ed. by K. Westphal (New York: Rowman \& Littlefield Publishers Inc., 1997).

Wittgenstein, Ludwig, Remarks on the Foundations of Mathematics, trans. by G. E. M. Anscombe, ed. by G. H. von Wright, R. Rhees, and G. E. M. Anscombe (Oxford: Basil Blackwell, 1978). 